\title{
Rainbow scarab Phaneaus vindex Macleay (Insecta: Coleoptera: Scarabaeidae) ${ }^{1}$
}

\author{
Thomson Paris, Barukh Rohde, and Philip E. Kaufman²
}

\section{Introduction}

Rainbow scarabs, Phanaeus vindex MacLeay, are members of the beetle family Scarabaeidae, which along with the family Geotrupidae, are commonly known as dung beetles (Bertone et al. 2004). Scarab beetles were the objects of worship in Ancient Egypt and the more spectacular varieties are made into jewelry (Woodruff 1973). The African dung-rolling beetle utilizes the sun, moon and stars as guides for walking in a straight line (Dacke et al. 2013). The genus Phanaeus MacLeay is distributed primarily in Neotropical habitats with 100 species, but also in the Neartic region with nine species and the West Indies with one. Dung beetles serve an important role in pasture ecosystems, which has resulted in their introduction around the world. The rainbow scarab, Phanaeus vindex MacLeay, has a bright exterior of metallic green, blue, and red interspersed with golden reflections (Figures 1 and 2).

\section{Synonymy}

Scarabaeus carnifex Linnaeus 1767

Phanaeus vindex Macleay,1819

Phanaeus vindex cyanellus Robinson, 1938

Phanaeus vindex rubervirens Robinson, 1948

(Arnaud 2002, Edmonds 1994)

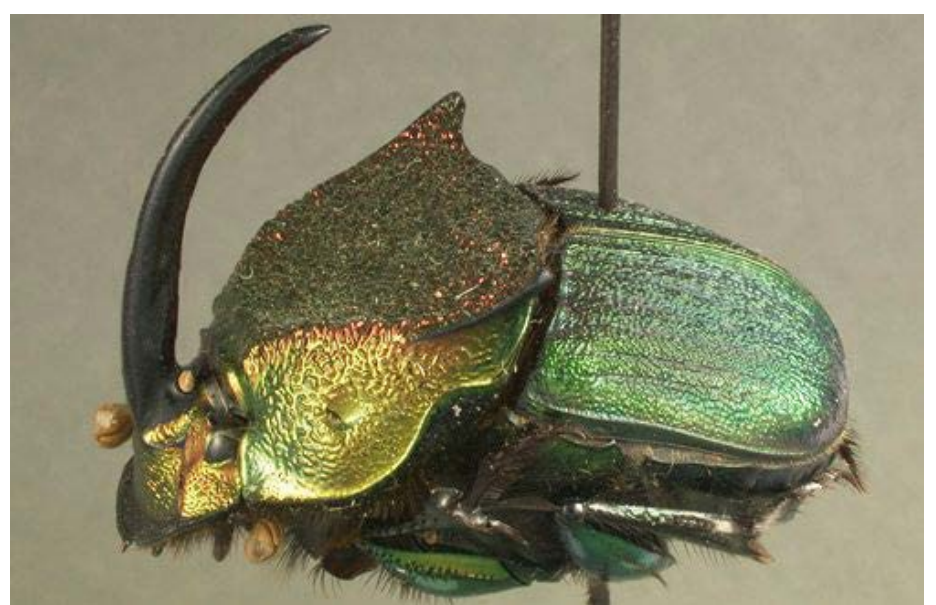

Figure 1. Red-green male Phanaeus vindex.

Credits: Paul Skelley

\section{Distribution}

The rainbow scarab is native to and found extensively in, the eastern United States from Massachusetts to South Dakota in the north and Texas to Florida in the south (Woodruff 1973). The Florida Keys and the Everglades are the only regions in Florida where the rainbow scarab has not been found (Woodruff 1973).

1. This document is EENY567, one of a series of the Entomology and Nematology Department, UF/IFAS Extension. Original publication date July 2013. This document is also available as a Featured Creature at http://entomology.ifas.ufl.edu/creatures. Visit the EDIS website at http://edis.ifas.ufl.edu.

2. Thomson Paris, graduate student, Entomology and Nematology Department; Barukh Rohde, Hunter College, affiliate faculty; Phillip E. Kaufman, associate professor, Entomology and Nematology Department, Institute of Food and Agricultural Sciences, University of Florida, Gainesville, FL 32611. 


\section{Description}

\section{Larvae}

The larvae are grublike, with a characteristic C-shaped body (Ratcliffe et al. 2002). The head is hardened and the body is soft and pliable (Woodruff 1973).

\section{Adults}

The adults are bulky, with an oval or elongate shape. From the top of the head to the back of the abdomen, males and females are about 1 to 2.2 centimeters long (Bertone et al. 2004). They have lamellate antennae. The males are easily identified by their metallic appearance and a large horn arising from the dorsal surface of the head. A similar species, Phaneus igneus (MacLeay), is also metallic, but has a smaller horn. Some males of Phaneus vindex, called minor males, have greatly reduced horns, but an examination of the differences in the posterior abdominal segments can be used in determing the gender. The females do not possess horns. The dorsal surface of the pronotum (thorax) is platelike, with the posterior ends of the male's pronotum pointed and slightly raised above the elytra (modified forewings of beetles, hardened into protective shields for the hind wings). The female's pronotum, by contrast, is not raised above the elytra. The pronotum and elytra in both the male and female have distinctive coloration. The pronotum generally has a metallic bronze and red coloration. The elytra generally are a metallic green. There are rare individuals that are dark blue to black in color, lacking all bronze-red coloration (Figures 3 and 4) (Woodruff 1973).

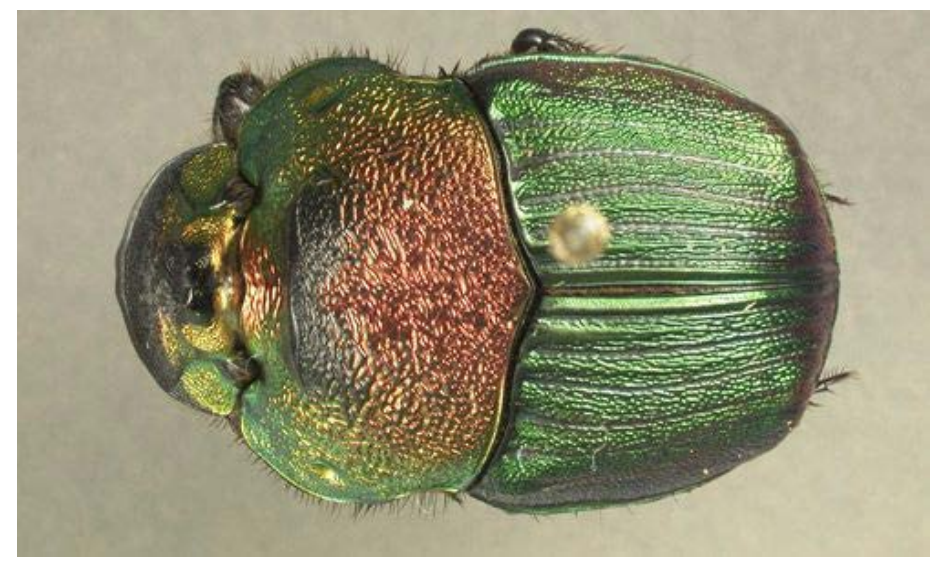

Figure 2. Red-green female Phanaeus vindex.

Credits: Paul Skelley

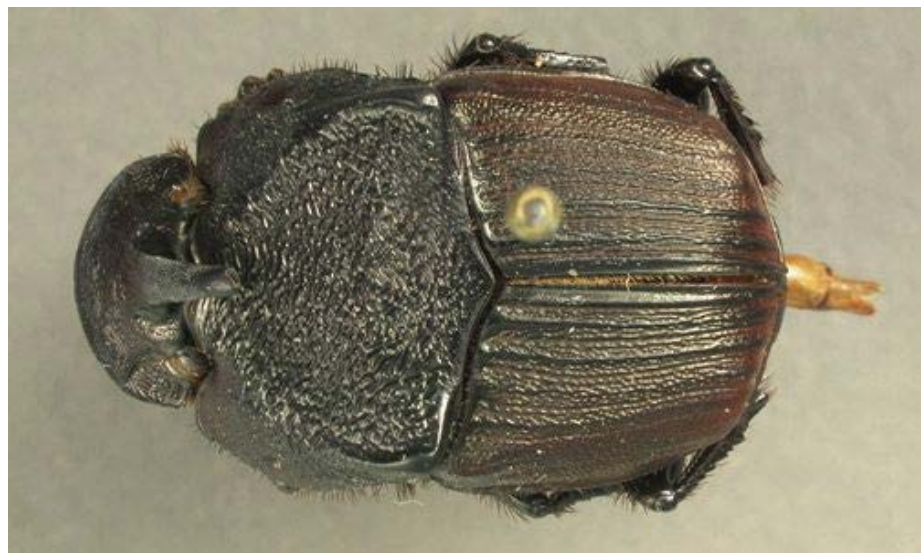

Figure 3. Blue-black male Phaneaus vindex. Credits: Paul Skelley

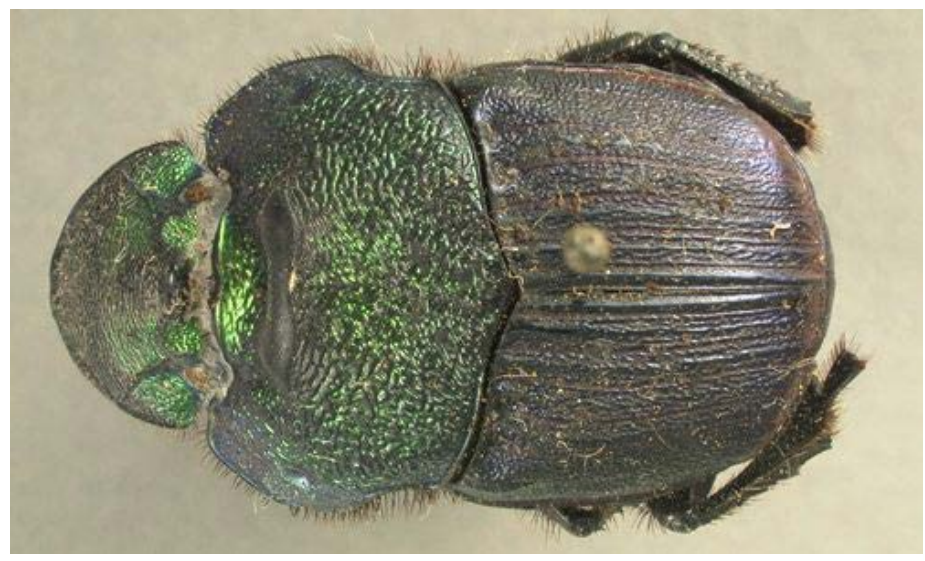

Figure 4. Green-blue female Phaneaus vindex. Credits: Paul Skelley

\section{Life Cycle}

Based on nest construction behavior, there are three types of dung beetles: tunnelers (paracoprids), dwellers (endocoprids), and rollers (telecoprids). Phanaeus vindex is an example of a tunneler (Ratcliffe et al. 2002). In tunneling species, both sexes create a tube by excavating the soil underneath the dung pat, culminating in a chamber below the surface of the dung pat (Figure 5). The tunneling excavations bring subsurface soil, called soilcasts, to the ground's surface. The brood ball is made underneath the dung pat (Ratcliffe et al. 2002). The brood ball consists of moist dung coated with soil to serve as food for the larva and young adult (Bertone et al. 2004). The ball of dung is pulled into the tunnel, a few centimeters below ground, and formed into brood, or feeding balls. The tunnels are filled with loose soil to protect the brood ball at the bottom of the tunnel (Bertone et al. 2006). Because tunnelers bring the dung underground, the tunnelers are the most sought after 
dung beetles for dung degradation (Kaufman and Wood 2012).

The brood ball is shaped nonuniformly, though it often appears pyriform or pear-shaped. Prior to making the brood ball, Phaneaus vindex performs a 'butting' action on the dung, thereby pushing it away from the original deposition site (Halffter and Matthews 1966). When the female begins to role the dung, this action attracts a male. The newly formed couple work to complete a ball of dung and also to construct a burrow, which may serve as an oviposition site or simply as a shelter (Halffter et al. 1974, Halffter and Matthews 1966, Thomas 2001). When female oviposistion occurs, an egg is placed at the point of the brood ball (Woodruff 1973). One or several brood balls are placed in the burrows which consist of dung coated with earth to preserve the dung quality (Halffter et al. 1974). In addition to the tunnel constructed for the brood ball (the primary tunnel), a second tunnel is constructed and stocked with a dung ball for food for the newly emerged adults and overwintering adults (the secondary tunnel) (Fincher 1972). Once oviposition in the brood ball is complete, the female ceases to care for the egg (and later the larva), although the female and her mate remain in the burrow (Halffter et al. 1974).

After hatching, a larva develops within the brood ball (Fincher 1972). Molting occurs twice during the larval stage, after which it pupates (transitions to adult stages) within the brood ball. In areas north of Florida, overwintering larvae remain below the frost line and rise from hibernation upon feeling the increasing temperatures of spring. The adults of Phaneaus vindex have also been known to overwinter (Blume and Aga 1976).

The final stage in the life cycle is the adult stage, which starts in the primary and secondary tunnels. The adult emerges from the tunnel in response to either temperature or rainfall (Ratcliffe et al. 2002). After emergence, adults will eventually search for a mate. Following mating, females then repeat the egg-laying cycle. Adults bury and consume dung as part of their diet, thereby providing valuable nutrient recycling in pasture systems (Bertone et al. 2006). Soil structure and composition seem to play a role in Phaneaus vindex survival and distribution. Sandy soils were found to be deleterious to Phaneaus vindex by causing larval dessication (Bertone et al. 2006, Fincher 1973).

In the laboratory, the total time from egg to adult emergence is two to six months (Fincher 1972). Under laboratory conditions, Phaneaus vindex adults can live for over a year. Under field conditions, survival is most likely much less than a year (Fincher 1972). One documented predator of Phaneaus vindex is the burrowing owl, Athene cunicularia (Molina), which has been found to have Phaneaus vindex fragments in its dung (Woodruff 1973).

The predatory mite Macrocheles amygdaligera (Berlese) is often found on the adult rainbow scarab. This predatory mite eats insect eggs, small insect larvae, and nematodes. Macrocheles amygdaligera appears to utilize the dispersal capabilities of the beetle in a symbiotic relationship known as phoresy, being transported from dung pat to dung pat by clinging to the beetle (Woodruff 1973).

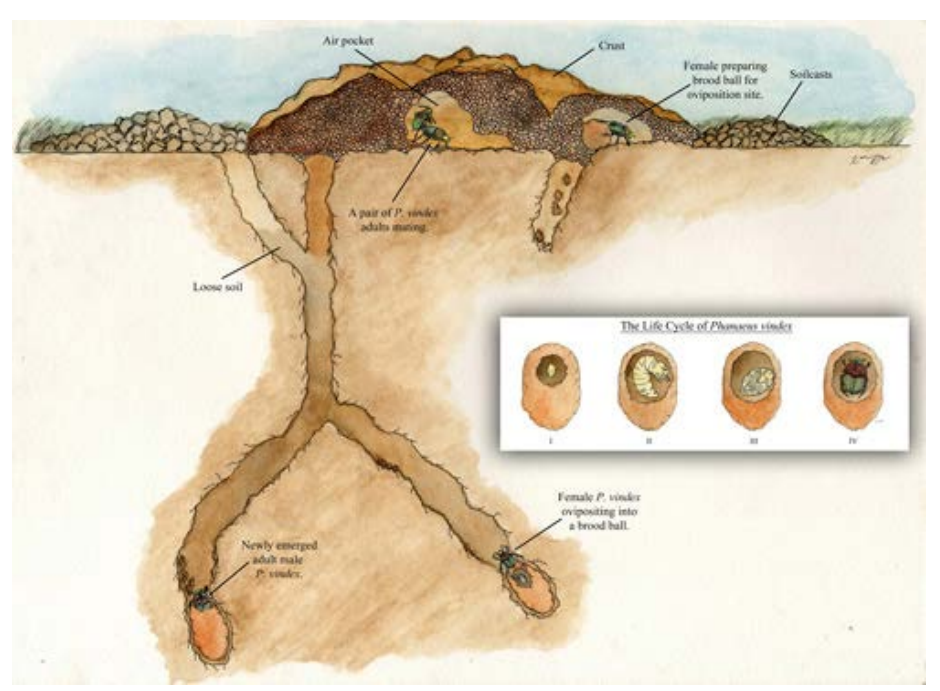

Figure 5. Life history of Phanaeus vindex.

Credits: Water color by Xavier Moss.

\section{Diet}

Dung beetles, in general, have been shown to prefer certain types of animal dung, which are listed in descending order: swine, opossum, dog, cow, raccoon, and horse (Bertone 2004, Fincher et al.1970). The level of attractivity of the swine and opossum dung was much higher than that of the others (Woodruff 1973). Phanaeus vindex also has a strong preference for human dung (Woodruff 1973). Dung beetles, as a whole, occupy a complex set of niches in the ecosystem related to the locations of dung in various habitats, soil types, and seasons of activity. A study in Germany (Wassmer 1995) indicated that some dung beetle species were more likely to be found in the forest rather than the pasture, in the pasture rather than the forest, and some were found in both forest and pasture habitats. However, seasonality was found to be much more critical for explaining dung beetle species diversity than habitat niches (Wassmer 1995). Phanaeus vindex's wide distribution is due to its tolerance 
for a wide variety of soil types (Fincher 1973). In eastern Texas, Phanaeus vindex appears to have a preference for open pastures that have sandy soils (Price and May 2009). This is curious due to sandy soil being deleterious for Phanaeus vindex's survival (Fincher 1973). In Texas, Phanaeus difformis LeConte often coexists with Phanaeus vindex. When this occurs, Phanaeus vindex's tendency to inhabit sandy soils is overruled and Phanaeus vindex inhabits clay soils (Blume and Alga 1976, 1978). In Florida, as in Texas, a species coexists with Phanaeus vindex: Phanaues igneus Macleay. Phanaeus igneus tends to inhabit sandy soils, while Phanaeus vindex inhabits clay soils (Edmonds 1994).

\section{Importance}

Infestation of humans with dung beetles is a rare occurrence. A different dung beetle of the genus Copris and family Scarabaeidae has been reported to infest humans in Sri Lanka (Rajapakse 1981). The most likely mechanism for infestation of dung beetles is ingestion of the larvae, while the chance of an oviposition event through the anus is low (Rajapakse 1981). There have been incidents where dung beetles accidentally infested humans, such as occurred with a group of 186 boy scouts in Pennsylvania in 1957. The beetles crawled into the ears of the boy scouts while they were sleeping. Bleeding was induced by the hind tibial spines of the beetles, but no secondary infections were reported (Mattuck and Fehn 1958).

Phanaeus vindex is known to be the intermediate host of a stomach worm, Physocerphalus sexalatus Molin, a nematode that infects swine. Swine obtain the stomach worm after ingesting adult Phanaeus vindex (Fincher et al. 1969). In the laboratory, the predatory mite Macrocheles amygdaligera, feeds on eggs of the stomach worm (Woodruff 1973).

Dung beetles are important in reducing waste accumulations of vertebrates, particularly ruminants (cattle, sheep, goats, etc.). This was dramatically depicted in Australia, which prior to the colonization of the continent by Europeans, was home to marsupials and no ruminants. The accumulated waste of introduced ruminants gradually resulted in a crisis that was alleviated by the introduction of several species of ruminant-specializing dung beetles to the Australian continent (Bornemissza 2006, Tyndale-Biscoe 1996).

Like many dung beetles, Phanaeus vindex was found to enrich clay soils as a result of feeding on a dung pile. Consumption of dung by adult beetles provides valuable nutrient recycling in pasture systems (Bertone et al. 2006).
Furthermore, harmful fly species such as the horn fly, Haematobia irritans (Linnaeus), may be outcompeted by populations of dung beetle larvae (Bertone 2004, Bertone et al. 2004).

\section{Conservation}

Trying to protect cattle from harmful parasites, while at the same time maintaining beetle populations, requires great prudence. Many pesticides used to treat parasitic worms in livestock will, if used for a long duration and without careful management, affect dung beetles adversely (Floate 1998, Lumaret and Errouissi 2002). The oral formulations of ivermectin have been shown to be less devastating to nontargets, which is in stark contrast to the sustainedrelease bolus of ivermectin, which has prolonged effects on nontargets (Lumaret and Errouissi 2002).

\section{Selected References}

Arnaud P. 2002. Les coleopteres du monde. Vol 28.

Phanaeini. Hillside Books. Canterbury. 151 pp.

Bertone MA. 2004. Dung Beetles (Coleoptera: Scarabaeidae and Geotrupridae) of North Carolina cattle pastures and their implications for pasture improvement. M.S.Thesis. North Carolina State University. Raleigh, NC. 159 pp.

Bertone MA, Green JT, Washburn SP, Poore SH, and Watson DW. 2006. The contribution of tunneling dung beetles to pasture soil nutrition. Plant Management Network International: Forage and Grazinglands. (19 June 2013).

Bertone MA, Watson W, Stringham M, Green J, Washburn S, Poore M, and Hucks M. (2004). Dung beetles of central and eastern North Carolina cattle pastures. North Carolina Cooperative Extension. North Carolina State University. Raleigh, NC. (19 June 2013).

Blume RB, Aga A. 1976. Phaneus difformis Leconte (Coleoptera: Scarabaeidae): Clarification of published descriptions, notes on biology, and distribution in Texas. The Coleopterists Bulletin 30: 199-205.

Blume RR, Aga A. 1978. Observations on ecological and phylogenetic relationships of Phanaeus difformis LeConte and Phanaeus vindex MacLeay (Coleopetera: Scarabaeidae) in North America. Southwestern Entomologist 3: 113-120.

Bornemissza G. (2006). We've dung it again! Our exotic solution to the dung problem in Australia. CSIRO. (28 June 2013). 
Dacke M, Baird E, Byrne M, Scholtz CH, Warrant EJ. 2013. Dung beetles use the Milky Way for orientation. Current Biology 23: 1-3.

Edmonds WD. 1994. Revision of Phanaeus Macleay, a New World genus of Scarabaeine dung beetles (Coleoptera: Scarabaeidae, Scarabaeinae). Contributions in Science, Natural History Museum of Los Angeles County 443: 1-105.

Fincher GT. 1972. Notes on the biology of Phanaeus vindex (Coleoptera: Scarabaeidae). Journal of the Georgia Entomological Society 7: 128-133.

Fincher GT. 1973. Nidification and reproduction of Phanaeus spp. in three textural classes of soil (Coleoptera: Scarabaeidae). The Coleopterists Bulletin 27: 33-37.

Fincher GT, Stewart TB, and Davis R. 1969. Beetle intermediate hosts for swine spirurids in southern Georgia. The Journal of Parasitology 55: 355-358.

Fincher GT, Stewart TB, and Davis R. 1970. Attraction of coprophagous beetles to feces of various animals. Journal of Parasitology 56: 378-383.

Floate KD. 1998. Off-target effects of ivermectin on insects and on dung degradation in southern Alberta, Canada. Bulletin of Entomological Research 88: 25-35.

Halffter G, Halffter V, and Lopez IG. 1974. Phanaeus behavior: food transportation and bisexual cooperation. Environmental Entomology 3: 341-345.

Halffter G, Matthews EG. 1966. The natural history of dung beetles of the subfamily Scarabaeinae (Coleoptera: Scarabaeidae). Folia Entomológica Mexicana 12-14: 1-313.

Kaufman PE, Wood LA. 2012. Indigenous and exotic dung beetles (Coleoptera: Scarabaeidae and Geotrupidae) collected in florida cattle pastures. Annals of the Entomological Society of America 105: 225-231.

Lumaret JP, Errouissi F. 2002. Use of anthelmintics in herbivores and evaluation of risks for the non target fauna of pastures. Veterinary Research 33: 547-562.

Mattuck DR, Fehn CF. 1958. Human ear invasions by adult Scarabaeid beetles. Journal of Economic Entomology 51: 546-547.

Price DL, May M. 2009. Behavioral ecology of Phanaeus dung beetles (Coleoptera:Scarabaeidae): Review and new observations. Acta Zoológica Mexicana (nueva serie) 25: 211-238.

Rajapakse S. 1981. Beetle marasmus. British Medical Journal 283: 1316-1317.

Ratcliffe BC, Jameson ML, Smith ABT. 2002. Family 34. Scarabaeidae Latreille 1802. In: Arnett RH Jr, Thomas MC, Skelley PE, Frank JH (eds.) American Beetles, Volume 2: Polyphaga: Scarabaeoidea through Curculionoidea. CRC Press, Boca Raton, 861 pp.

Thomas ML. (2001). Dung beetle benefits in the pasture ecosystem. ATTRA. (28 June 2013).

Tyndale-Bisoce M. 1996. Australia's introduced dung beetles: Original releases and distributions. CSIRO Entomology Technical Report. No. 62. 149 pp.

Wassmer T. 1995. Selection of the spatial habitat of coprophagous beetles in the Kaiserstuhl area near Freiburg (SW-Germany). Acta Ecologica 16: 461-478.

Woodruff RE. 1973. Arthropods of Florida and neighboring land areas. The Scarab Beetles of Florida, Volume 8. Florida Department of Agriculture and Consumer Services. Contribution No. 260, Bureau of Entomology, Gainesville. $220 \mathrm{pp}$.

Woodruff RE. 1973. The scarab beetles of Florida. Part I, the Laprosticti (subfamilies Scarabaeinae, Aphodiinae, Hybosorinae, Ochodaeinae, Geotrupinae, Acanthocerinae). Florida Department of Agriculture and Consumer Services. 